\title{
A MICRO-CT ASSESSMENT OF DENTINAL DAMAGE AFTER SHAPING OF OVAL-SHAPED ROOT CANALS
}

\author{
Irina Tsenova-Ilieva, Radosveta Vassileva, Emilia Karova \\ Department of Conservative Dentistry, Faculty of Dental Medicine, Medical \\ University - Sofia, Bulgaria.
}

\section{SUMMARY}

Purpose: The aim of the current study was to assess the dentinal damage after shaping of oval-shaped root canals of lower incisors with SAF by means of micro-computed tomography.

Materials and methods: Twenty single-rooted, nonendodontically treated lower incisors with straight roots were included in the experiment. The specimens were scanned using high-resolution micro-computed tomographic imaging before and after root canal preparation with $1.5 \mathrm{~mm}$ Self-adjusting file. Preoperative and postoperative cross-sectional images of the teeth were screened to identify the presence of dentinal defects. The McNemar test was used to determine significant differences before and after instrumentation. The level of significance was set at pd"0.05.

Results: The Self-adjusting file system insignificantly increased the percentage rate of microcracks in root canals of lower incisors compared with preoperative specimens ( $>>0.05)$.

Conclusions: The shaping of oval-shaped root canals with Self-adjusting file did not result in significant damage of radicular dentin.

Keywords: root canalshaping, dentinal microcracks, Self-adjusting filesystem, micro-computed tomography

\section{INTRODUCTION}

The main goal of the initial endodontic therapy is to eliminate the existing microorganisms by cleaning and shaping of the root canal, thus ensuring its tight-seal and threedimensional filling. Recently, various rotary nickel-titanium (NiTi) systems are preferred over hand instrumentation for enlargement of the root canal system due to their increased cutting efficiency, exclusive superelasticity and flexibility, as well as minimized procedural errors $[1,2,3]$. Despite their favorable qualities, these files can exert a different amount of stress onto the root canal wall, causing dentinal defect formation $[1,3,4]$. It is speculated that the occurrence of microcracks is related to the type of the alloy of the instruments, their taper, tip design, cross-section and the kinematics type [5, 6]. Minor defects such as craze lines and partial cracks can propagate over time into vertical root fracture (VRF), which is one of the most common reasons for tooth loss [3, 4, 7].
The constant demand for implementation of new rotary NiTi systems reducing the operators' fatigue and the time required for thorough root canal debridement and shaping, led to the appearance of the so-called single-file techniques [1]. The recently introduced Self-adjusting filesystem (ReDent-Nova, Raanana, Israel) (SAF) has gained increased popularity among dental practitioners. These files represent an attempt to overcome some of the limitations of NiTi files and to provide three-dimensional adaptation to the root canal walls both longitudinally and cross-sectionally. Due to their unique design, SAF files respect the canal anatomy, preserve its flat form and avoid canal straightening and transportation $[8,9]$. Moreover, the promising characteristics of these instruments enable shaping oval-shaped root canals in a safe manner, without unnecessarily enlarging their diameter.

The aim of the current study was to assess the dentinal damage after shaping of oval-shaped root canals of lower incisors with SAF by means of micro-computed tomography.

\section{MATERIALS AND METHODS}

Tooth selection and sample preparation

All samples in the experiment were recruited from a pool of freshly extracted teeth from the Department of Oral and Maxillofacial Surgery, Faculty of Dental Medicine, Medical University - Sofia, Bulgaria. Overall thirty-six intact mandibular incisors were extracted due to periodontal lesions. The extractions were performed atraumatically to prevent crack formation during the procedures.

Immediately after extraction, all root surfaces were gently cleaned using an ultrasonic tip under water cooling to remove calculus and soft tissue debris. All teeth were inspected under a stereomicroscope at $\mathrm{x} 40$ to detect the root surfaces and those exhibiting root caries, incomplete root formation, fracture, external cracks or resorptions were excluded from the experiment and replaced with new ones. Selection of teeth with oval-shaped canals was done on the basis of digital radiographs by using a standardized technique with buccal-lingual and mesial-distal projections. The teeth included in the experiment were with buccolingual to mesiodistal ratio $\geq 2.5: 1$, respectively. Twenty single-rooted, non-endodontically treated lower incisors with straight roots $\left(<5^{\circ}\right)$ were finally selected and stored in distilled water at $37^{\circ} \mathrm{C}$ until further evaluation. To ensure standardization, all 
teeth were horizontally section using a diamond bur under copious water cooling at the cementoenameljunction, leaving roots at approximately $15,5 \pm 0.5 \mathrm{~mm}$ length

All specimens were covered with plastic wrap, mounted in the device and scanned prior instrumentation using the Bruker-SkyScan 1272 tomograph (Bruker-microCT, Kontich, Belgium) at $100 \mathrm{kV}, 100 \mu \mathrm{A}$ and voxel sizeof 10 $\mu \mathrm{m}$. X-rays were filtered with a $0.11 \mathrm{~mm}$-thickcopper filter. Images were reconstructed and analyzed with the following programs: DataViewerv. 1.5.2.4 (BrukermicroCT), CTan (BrukermicroCT) and CTvoxv. 3.2.0.0 (BrukermicroCT). Crack identificationwas performed according to a previously published methodology. Thepresence of radiolucent lines in micro-CT cross-section images was identified ascracks.

\section{Root canal instrumentation with SAF}

All canals were negotiated with a size $10 \mathrm{~K}$-file (DentsplySironaEndodontics, Ballaigues, Switzerland)till its tip was visible at the apical foramen and working length (WL) was determined $1 \mathrm{~mm}$ short of this measurement.A glide path was created by using Pre-SAF 20/.04 (ReDent-Nova, Raanana, Israel).

A 1.5-mm diameter SAF (ReDent-Nova, Raanana, Israel) at full working length was attached to the RDT head (ReDent-Nova) and operated for 4 minutes by using vibrating handpiece (Gentle-Power Lux 20LP; KaVo, Biberach, Germany) at a frequency of $83.3 \mathrm{~Hz}(5000 \mathrm{rpm})$ and amplitude of $0.4 \mathrm{~mm}$. Removal of dentin was performed with the back-and-forth motion caused by the combination of the vibrations of the file and the pecking motion applied by the operator. Constant irrigation of the canals was provided by delivery of $5 \mathrm{~mL} / \mathrm{min}$ saline by using a special irrigation apparatus (VATEA; ReDent-Nova).

During the shaping of the root canal, all specimens were mounted in silicon mold to simulate the periodontal ligament.

\section{Dentinal microcrack evaluation}

After the post-operative scanning, reconstructed images were transferred to the DataViewer program (version 1.5.2.4, Bruker microCT), and 3-dimensional reimaging was performed. In this way, coronal, sagittal, and transaxial axes images were obtained for each sample. Before and after canal preparation, the cross-sectional images from all the scans were evaluated. Ultimately, a total of 61790 cross-sectional images of all teeth were obtained (30 895 images after each scan). The images of the samples before and after preparation were opened simultaneously and compared twice. All radiolucent lines (e.g., a craze line, a partial crack, fractures, or microcracks) were defined as dentinal microcracks.

\section{Statistical analysis}

The number of microcracks was determined as a percentage foreach group. Data were analyzed using the IBM SPSS 23 statistical software program (version 23; IBM, Chicago, IL). The McNemar test was used to determine significant differences before and after instrumentation. The level of significance was set to $\mathrm{p} \leq 0.05$

\section{RESULTS}

The total number of cross-sectional images after the initial scanning of all twenty non-endodontically treated roots were 30895 . Preexisting microcracks were observed in 601 of them $(1.95 \%)$. Only 85 out of $30895(0.28 \%)$ of the cross-sectional images after shaping with SAF exhibited new microcracks $(\mathrm{p}>0.05)$ (fig. 1). All dentinal defects registered in the postoperative data sets were already present in the corresponding preoperative images. There was no correlation between the location and the type of cracks observed.

In 15 samples, a separation between enamel and dentin was observed. These findings were not considered as dentinal defects since their location was at the cementodentinal junction and not in the root dentin wall itself (fig.2).

Fig. 1. Representative micro-CT cross-sections of the apical third of oval-shaped rootsof lower incisors before and after root canal preparation with SAF. Microcracks are indicated with red arrows.
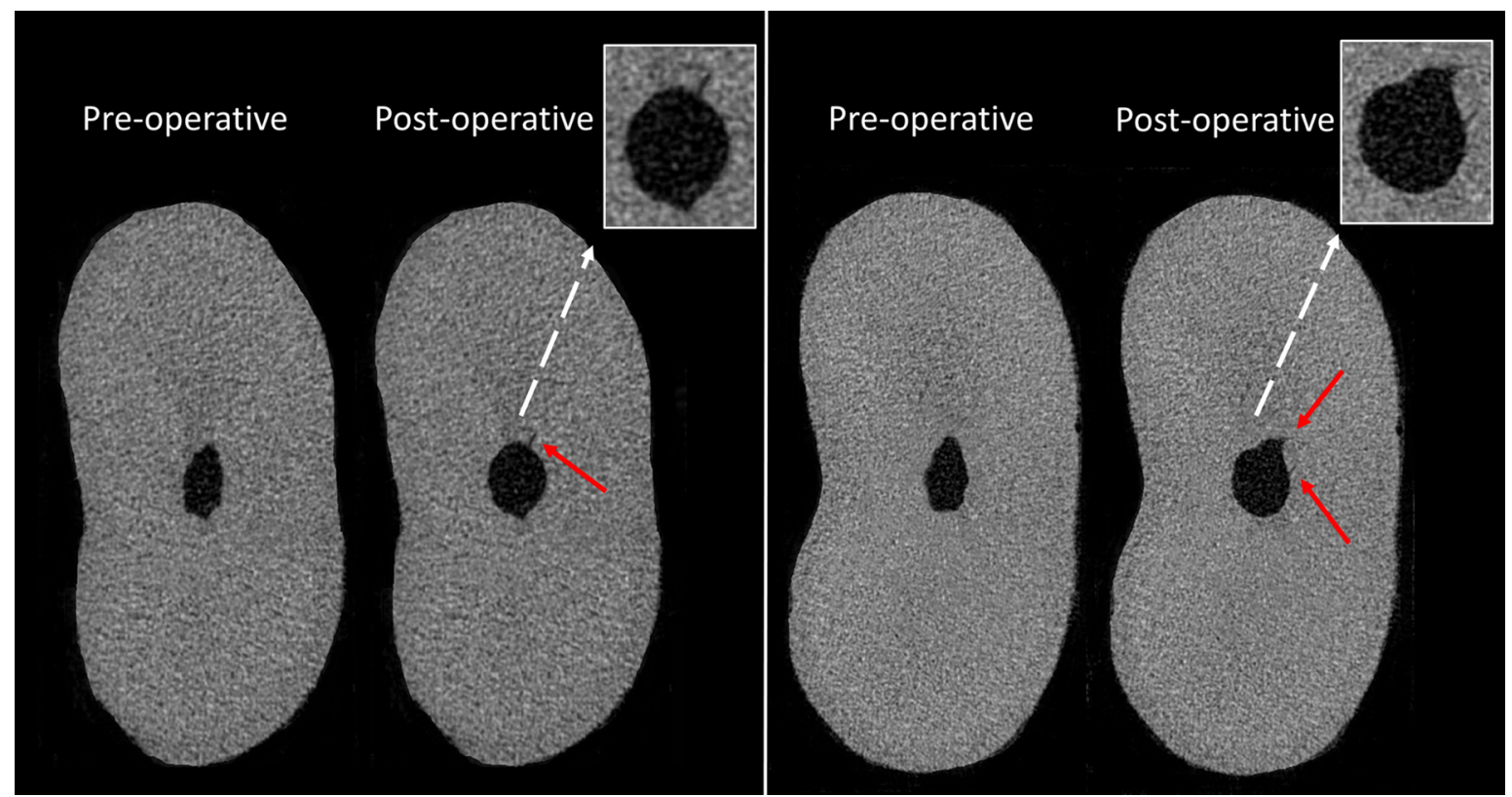
Fig. 2. The separation between enamel and dentin (green arrows). A) Preoperative view, B) Postoperative view of the same cross-section.

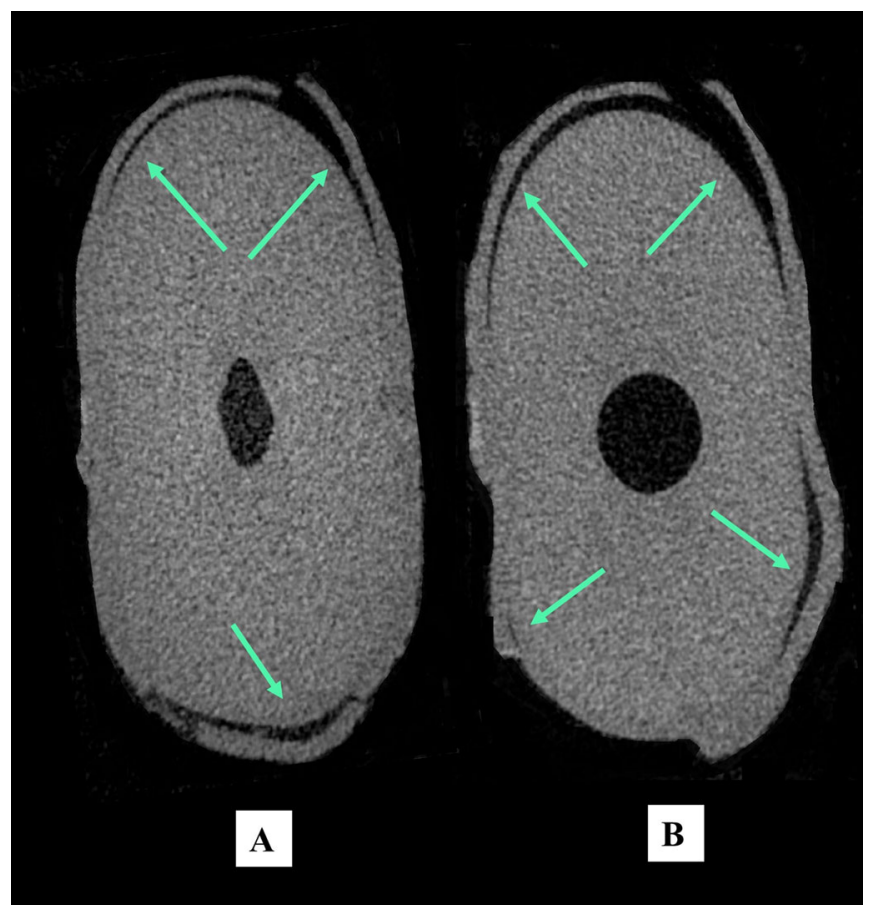

\section{DISCUSSION}

Reports in literature lack consensus in sample selection and storage conditions of the specimens for micro-CT investigations. In the current experimentstringent inclusion criteria were applied in selecting oval-shaped root canals of mandibular incisors with close anatomical characteristics. Our decision was based on the high prevalence of such root canal configuration reported previously by other authors [10]. Wu et al. found the presence of oval canals in the apical portion of about $25 \%$ of the examined cases. Their prevalence is $25-30 \%$ in the distal roots of mandibular molars and more than $50 \%$ in the groups of the mandibular incisors and maxillary second premolars [10].Furthermore, a finite-element analysis showed that stress concentrations were highest in oval roots, presenting greater buccal-lingual diameter.It is assumed that the lower thickness of the mesial and distal root canal walls might cause higher strain accumulation thus increasing the risk of microcracks initiation and propagation[11]. Oval root canals present sharpened notch at the edge of the oval extension, which compared to round canals, is a site more susceptible to crack initiation when mesiodistal forces are applied from the inside out $[1,7]$. In an attempt to enable better stress distribution during the shaping procedures, we simulated PDL in our experimental design, as suggested previously [4].

Recently, micro-computed tomographyhas gained an increasing significance in endodontic investigations due to its non-destructive and reproducible nature, great accuracyin the examination of root canal anatomy and quantitative and qualitativeevaluation of the outcome of different endodontic procedures [2, 12, 13, 14]. The most important advantage of this method is that microcracks evaluation can be done at each step throughout various endodontic procedures without hampering the initial sample[14]. This methodology allows further overlapping on the same specimens by subsequently tracing dentinal defects after endodontic retreatment, post preparation and post-removal procedures. As a result of this, one and the same sample can serve as its own control $[2,15]$.

Two successive micro-CT scans were performed in the present study. The first one aimed to establish the preexisting dentinal defects in non-endodontically treated teeth. The second one - to assess the dentinal damage after shaping of oval-shaped root canals with SAF.Only intact lower incisors, with no external defects after stereomicroscopic observation were included in the current experiment. Nevertheless, $1.95 \%$ of the cross-sectional images obtained after the initial scanning, displayed preexisting defects. The findings are consistent with other studiesexhibiting dentinal microcracks in intact roots $[15,16$, 17]. It is noteworthy to mention that fifteen samples exhibited separation of cement and dentin at different levels along the root length. These findings were not registered as dentinal defects as they appeared at the cementodentinal junction and not in the dentinal wall itself. We assume that they might be due to the initial cleaning of the root surface from calculus and soft tissue debris. Similar findings were observed in the study of Rödig et al. (2019) [17].

In an attempt to obtain an optimal preparation form with a minimally-invasive technique, all samples were shaped with $1.5 \mathrm{~mm}$ SAF file. The better performance of SAF system might be due to its thin-walled, hollow, slightly abrasive NiTi lattice-like form which allows it to be easily compressed and to adapt to the form of the root canal without unnecessarily weakening it. The unique design and vibration movement of the file enables removal of a thin, uniform layer of dentin along the root canal. It preserves its original shape without enlarging theapical diameter [8, 9].

Results from the present study confirmed the ability of SAF to preserve the structural integrity of the root canal dentin and to reduce the risk of defect formation [4] as an insignificant number of new defects were registered $(0.28 \%)$. No propagation of preexisting cracks was observed after the analysis of the cross-sectional images of the two scans. These findings confirmthe statements of Bayram et al. (2017) and Zuolo et al. (2017) who reported no new formation of dentinal microcracks after instrumentation with SAF system $[18,19]$. The insignificant struc- 
tural alterations of dentinafter using the file might be due to its constructional characteristics and reducedlevel of forces generated during its use. In their finite-element analysis, Kim et al. (2008) claimedthat a greater amount of stress is generated by more rigid files with a solid body and higher taper [20].

\section{CONCLUSIONS}

Within the limitations of this study, the shaping of oval-shaped root canals with Self-adjusting file did not result in significant damage of radicular dentin. The microcomputed tomography presented as a highly-accurate tool for dentinal microcrack visualization.

\section{REFERENCES:}

1. Tsenova I, Vassileva R, Karova E. Incidence of dentinal microcracks after root canal preparation with two reciprocating systems: a stereomicroscopic study. J of IMAB. 2018 Oct-Dec;24(4):2245-2249. [Crossref].

2. Versiani A, Souza E, De-Deus G. Critical appraisal of studies on dentinal radicular microcracks in endodontics: methodological issues, contemporary concepts, and future perspectives. Endod Topics. 2015 Nov;33(1):87-156. [Crossref]

3. Karova E. Properties of nickeltitanium alloy. In Nickel-titanium rotary instruments - a guide for students. Sofia: Valdex Ltd. 2015. 120 p.

4. Liu R, Hou BX, Wesselink PR, Shemesh $H$. The incidence of root microcracks caused by 3 different single-file systems versus the ProTaper system. J Endod. 2013 Aug; 39(8): 1054-1056. [PubMed] [Crossref]

5. Al-Zaka IM. The effects of canal preparation by different NiTi rotary instruments and reciprocating WaveOne on the incidence of dentinal defects. M Dent J. 2012;9(2):137142. [Crossref]

6. Kim HC, Lee MH, Yum J, Versluis A, Lee CJ, Kim BM. Potential relationship between design and vertical root fracture. J Endod, 2010 Jul;36(7):1195-1199. [PubMed] [Crossref]

7. Tsenova I, Vassileva R, Karova E. The ability of root canal cleaning and shaping procedures to initiate dentinal radicular microcracks. Int $J$ Sci Res. 2018 Aug;7(8):1558-1565.

8. Hof R, Perevalov V, Eltanani M,
Zary R, Metzger Z. The self-adjusting file (SAF). Part 2: mechanical analysis. J Endod. 2010Apr;36(4):691-6. [PubMed] [Crossref]

9. Metzger Z, Teperovich E, Zary R, Cohen R, Hof R. The self-adjusting file (SAF). Part 1: respecting the root canal anatomy-a new concept of endodontic files and its implementation. J Endod, 2010 Apr;36(4):679690. [PubMed] [Crossref]

10. Wu MK, Roris A, Barkis D, Wesselink PR. Prevalence and extent of long oval canals in the apical third. Oral Surg Oral Med Oral Pathol Oral RadiolEndod, 2000 Jun;89(6):739743. [PubMed] [Crossref]

11. Lertchirakarn V, Palmara JE, Messer HH. Patterns of vertical root fracture: factors affecting stress distribution in the root canal. J Endod. 2003 Aug;29(8):523-528. [PubMed] [Crossref]

12. De-Deus G, Belladonna FG, Silva EJNL, Souza EM, Carvalhal JCA, Perez R, et al. Micro-CT assessment of dentinal microcracks after root canal filling procedures. IntEndod J.2017 Sep;50(9):895-901. [PubMed] [Crossref]

13. De-Deus G, Carvalhal JCA, Belladonna FG, Silva EJNL, Lopes RT, Moreira Filho RE, et al. Dentinal microcrack development after canal preparation: a longitudinal in situ micro-computed tomography study using a cadaver model. J Endod. 2017 Sep;43(9):1553-1558. [PubMed] [Crossref]

14. Tsenova I, Vassileva R, Karova E. Damages to radicular dentin during root canal filling and retreatment procedures: analysis, evaluation methods and methodological issues. Int J Sci Res. 2018 Oct;7(10):524-533.

15. De-Deus G, Belladonna FG, Marins JR, Silva EJ, Neves AA, Souza $\mathrm{EM}$, et al. On the casuality between dentinal defects and root canal preparation: a micro-CT assessment. Braz Dent J. 2016 Oct-Dec;27(6):664-669. [PubMed] [Crossref]

16. Oliveira BP, Câmara AC, Duarte DA, Heck RJ, Antonino ACD, Aguiar CM. Effect of reciprocating systems and working lengths on apical microcrack development: a microCT study. Braz Dent J. 2017 NovDec;28(6): 710-714. [PubMed] [Crossref]

17. Rödig T, Krämer J, Müller C, Wiegand A, Haupt F, Rizk M. Incidence of microcracks after preparation of straight and curved root canals with three different NiTi instrumentation techniques assessed by micro-CT. Aust Endod J. Dec;45(3):394-399. [PubMed] [Crossref]

18. Bayram HM, Bayram E, Ocak M, Uygun AD, Celik HH. Effect of ProTaper Gold, Self-Adjusting File, and XP-endo Shaper instruments on dentinal microcrack formation: a micro-computed tomographic study. $J$ Endod. 2017 Jul;43(7):1166-1169. [PubMed] [Crossref]

19. Zuolo ML, De-Deus G, Belladonna FG, Silva EJ, Lopes RT, Souza EM, et al. Micro-computed tomography assessment of dentinal microcracks after root canal preparation with TRUShape and Self-Adjusting 
File systems. J Endod. 2017 Apr; son of forces generated during root using a three-dimensional finite-ele43(4):619-622. [PubMed] [Crossref] canalshaping and residual stresses of ment analysis. J Endod. 2008 Jun; 20. Kim HC, Cheung GS, Lee CJ, three nickel-titanium rotary files by 34(6):743-747. [PubMed] [Crossref] Kim BM, Park JK, Kang SI. Compari-

Please cite this article as: Tsenova-Ilieva I, Vassileva R, Karova E. A micro-CT assessment of dentinal damage after shaping of oval-shaped root canals. J of IMAB. 2020 Jul-Sep;26(3):3288-3292.

DOI: https://doi.org/10.5272/jimab.2020263.3288

Received: 12/09/2019; Published online: 13/08/2020

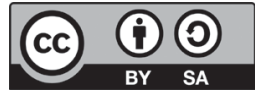

\author{
Address for correspondence: \\ Irina Tsenova-Ilieva \\ Department of Conservative Dentistry, Faculty of Dental Medicine, Medical \\ University - Sofia, Bulgaria \\ 1, St GeorgiSofiyskiblvd., 1413 Sofia \\ E-mail: irinatsenova@yahoo.com,
}

